\title{
Aberrant Hepatic Processing Causes Removal of Activation Peptide and Primary Polymerisation Site from Fibrinogen Canterbury (Aa 20 Val $\rightarrow$ Asp)
}

Stephen O. Brennan, Bruce Hammonds, and Peter M. George

Molecular Pathology Laboratory, Biochemistry Unit, Christchurch Hospital, Christchurch, New Zealand

\begin{abstract}
A novel mechanism of molecular disease was uncovered in a patient with prolonged thrombin time and a mild bleeding tendency. DNA sequencing of the fibrinogen A $\alpha$ chain indicated heterozygosity for a mutation of $20 \mathrm{Val} \rightarrow$ Asp. The molar ratio of fibrinopeptide $A$ to $B$ released by thrombin was substantially reduced at 0.64 suggesting either impaired cleavage or that the majority of the variant $\alpha$-chains lacked the $A$ peptide. The latter novel proposal arises from the observation that the mutation changes the normal ${ }^{16} \mathbf{R} \mathbf{G} \mathbf{P}$ $R V^{20}$ sequence to $R$ G $P R$ creating a potential furin cleavage site at Arg 19. Synthetic peptides incorporating both sequences were tested as substrates for both thrombin and furin. There was no substantial difference in the thrombin catalyzed cleavage. However, the variant peptide, but not the normal, was rapidly cleaved at Arg 19 by furin. Predictably intracellular cleavage of the A $\alpha$-chain at Arg 19 would remove fibrinopeptide $A$ together with the $G P R$ polymerisation site. This was confirmed by sequence analysis of fibrinogen $A \alpha$ chains after isolation by SDS-PAGE. The expected normal sequence was detected together with a new sequence ( $D$ V E R H Q S A-) commencing at residue 20. Truncation was further verified by nonreducing SDSPAGE of the $\mathrm{NH}_{2}$-terminal disulfide knot which indicated the presence of aberrant homo- and heterodimers. (J. Clin Invest. 1995. 96:2854-2858.) Key words: coagulation • furin - proprotein • protein synthesis $\cdot$ dysfibrinogenemia
\end{abstract}

\section{Introduction}

Fibrinogen is a $340-\mathrm{kD}$ dimeric disulfide linked molecule with each half consisting of three polypeptide chains; $\mathrm{A} \alpha, \mathrm{B} \beta$, and $\gamma$ (1) with molecular weights of $66,062,54,358$, and 48,529 , respectively. The final step of the coagulation cascade and the first step of fibrin polymerisation involves the thrombin catalyzed cleavage of the Arg-Gly bond between residues 16 and 17 of the A $\alpha$ chain of fibrinogen (2). The release of fibrinopeptide A exposes a new Gly Pro Arg $\mathrm{NH}_{2}$-terminal sequence which initiates polymerisation by docking to a preexisting site located in the $\mathrm{COOH}$-terminal domain of the fibrinogen molecule, and

Address correspondence to Stephen O. Brennan, Clinical Biochemistry Unit, Canterbury Health Laboratories, Christchurch Hospital, Christchurch, New Zealand. Phone: 64-3-364-0550; FAX: 64-3-364-0750; E-mail: pgeorge@chmeds.ac.nz

Received for publication 20 April 1995 and accepted in revised form 24 August 1995.

J. Clin. Invest.

(C) The American Society for Clinical Investigation, Inc. 0021-9738/95/12/2854/05 \$2.00

Volume 96, December 1995, 2854-2858 centred close to $\gamma 363 \mathrm{Tyr}$ (3). A similar thrombin catalysed reaction results in release of the $\mathrm{B}$ peptide from the $\mathrm{B} \beta$ chain.

The three fibrinogen chains are synthesized in the liver and assembled into functional fibrinogen molecules before export from the hepatocyte (4). At least two intracellular endoproteases are involved in the export and posttranslational modification of the molecule. In the endoplasmic reticulum signal peptidase removes the prepeptide from all three chains and a postGolgi cleavage removes a 'pro' peptide from the $\mathrm{COOH}$-terminal of the $A \alpha$-chain (5). This fibrinogen convertase has not been identified but an hepatic convertase, first described in 1988, cleaves the propeptide from proalbumin at its Arg Arg (6) site and has been shown to have a preference for cleavage at $\operatorname{Arg}$ X Y Arg over X Y Arg Arg sequences (7). This endogenous $\mathrm{Ca}^{2+}$-dependent microsomal serine protease has the same dibasic specificity as recombinant furin (8), a microsomal protease expressed at high mRNA levels in the liver. Indeed, furin and the endogenous protease also have the same $\mathrm{pH}$ optimum and inhibitory spectrum. Thus the present evidence suggests that they are the same enzyme $(9,10)$. The Arg Pro Val Arg cleavage sequence at the $\mathrm{COOH}$-terminal of the A $\alpha$-chain, conforms to the furin processing motif $(5,9)$. After cleavage, the newly exposed P1 Arg would be expected to be removed by carboxypeptidase $\mathrm{H}$ ( 11 ), or a similar circulatory carboxypeptidase to give the mature chain with its $\mathrm{COOH}$-terminal valine.

Similar dibasic sequences also mark the intracellular proprotein processing sites in peptide hormones, growth factors, plasma proteins, receptors, bacterial toxins, viral envelope glycoproteins, and other liver-derived coagulation factors, including proprothrombin, profactors IX, X, and XII, and proproteins $\mathrm{C}, \mathrm{S}$, and $\mathrm{Z}(7,9,12)$. Human mutations that abolish these dibasic processing motifs result in diseases with pathologies dependent on the function of the mature product. For example, mutations in the Arg Pro Lys Arg processing site of profactor IX, at -1 Arg $\rightarrow$ Ser (13) or $-4 \operatorname{Arg} \rightarrow$ Gln (14), result in hemophilia since the uncleaved precursors are unable to be activated by factor XIa. The mutation of $-1 \mathrm{Arg} \rightarrow$ Ser in the insulin proreceptor results in noninsulin dependent diabetes (15), while mutations of either the -1 or -2 Arg of proalbumin (10) result in circulating proalbumin with no associated pathology. Most importantly, the mutation of $+1 \mathrm{Asp} \rightarrow \mathrm{Val}$ in proalbumin Blenheim changes the processing sequence from Val Phe Arg Arg Asp to Val Phe Arg Arg Val and this prevents processing of the proalbumin precursor $(10,16)$.

Here we report a new disease mechanism in a patient with a prolonged thrombin time. The mutation introduces an inappropriate proprotein cleavage sequence at residue 19 of the $\mathrm{A} \alpha$ chain of fibrinogen and is the first report of a disease being caused by this mechanism. Here the mutation results in removal of fibrinopeptide A and the primary Gly Pro Arg polymerisation sequence before the fibrinogen molecule enters the circulation.

\section{Methods}

Materials. The protease inhibitors, E-64 (thiol), o-phenanthroline (metalo) and pepstatin (aspartyl) were obtained from Boehringer Mannheim 
Biochemicals (Indianapolis, IN). Bothrops atrox venom (atroxin) was obtained from Sigma Chemical Co. (St. Louis, MO) and stored at 5 $\mathrm{mg} / \mathrm{ml}$ in water at $-20^{\circ} \mathrm{C}$. Human $\alpha$-globin was prepared by chromatography of hemoglobin A globin on CM-cellulose in $6 \mathrm{M}$ urea.

Plasma analysis. Plasma was prepared from trisodium citrate anticoagulated whole blood and thrombin and reptilase clotting times were performed by standard protocols. Fibrinogen functional concentrations were determined using the Clauss method and molar concentrations were determined by quantification of the amount of fibrinopeptide $B$ released from plasma on treatment with thrombin. For fibrinopeptide release assays $50 \mu \mathrm{l}$ of plasma and $50 \mu \mathrm{l}$ of $50 \mathrm{mM}$ Tris $\mathrm{HCl}, 50 \mathrm{mM}$ $\mathrm{NaCl}, 10 \mathrm{mM} \mathrm{CaCl}_{2}$ were incubated with $5 \mu 1$ of $10 \mathrm{mM}$ phenanthroline and $1 \mathrm{U}$ of bovine thrombin (Parke Davis Thrombostat, Ann Arbor, MI). After $5 \mathrm{~min} 100 \mu \mathrm{l}$ of $49 \mathrm{mM}$ phosphate buffer $\mathrm{pH} 2.9$ was added, the solution boiled for $5 \mathrm{~min}$, microfuged, and $50 \mu \mathrm{l}$ of the supernatant injected on to a Nova Pac C-18 column. The column was eluted with a linear gradient from 25 to $50 \%$ solvent B where the initial solvent, A, was $49 \mathrm{mM}$ phosphate buffer $\mathrm{pH} 2.9$ and solvent B was an equal mixture of A and acetonitrile (8).

Fibrinogen analysis. Fibrinogen was purified by precipitation with $20 \%$ saturated ammonium sulphate $\left(20^{\circ} \mathrm{C}\right)$, after standing $\left(4^{\circ} \mathrm{C}\right)$ for 30 min the precipitate was collected by centrifugation and washed twice with $20 \%$ saturated ammonium sulphate before being dissolved in water at $37^{\circ} \mathrm{C}$.

DNA amplification. Genomic DNA was isolated from white blood cells and oligonucleotide primers were synthesized on an DNA synthesizer (390; Applied Biosystems, Inc., Foster City, CA). The A $\alpha$ primer pair targeted nucleotides 1111-1130 (5'ATT GCT GTT GCT CTC TTT TG $3^{\prime}$ ) and 1290-1309 (5' AAT CTC CTG CTT CCC CCG CT $\left.3^{\prime}\right)$, and the B $\beta$ pair targeted 3187-3206 (5'GGG TGT TGG AAT AGT TAC AT $\left.3^{\prime}\right)$ and 3495-3515 (5'CTG CCA TGA CTA CAG GCT TT 3') (17). These primers flank the second exon of each chain. After a hot start $\left(98^{\circ} \mathrm{C}, 10 \mathrm{~min}\right)$ Taq polymerase (Boehringer Mannheim Biochemicals) was added to the amplification mixture which contained $100 \mathrm{ng}$ of DNA, 50 pmol primers, and $200 \mu \mathrm{M}$ dNTPs. 30 amplification cycles were performed of denaturation $\left(94^{\circ} \mathrm{C}, 30 \mathrm{~s}\right)$, annealing $\left(60^{\circ} \mathrm{C}\right.$, $30 \mathrm{~s})$, and extension $\left(72^{\circ} \mathrm{C}, 30 \mathrm{~s}\right)$, with a final extension of $7 \mathrm{~min}$. The PCR product was gel purified and sequenced directly by the dideoxy chain termination method using $\left[{ }^{33} \mathrm{P}\right]$ ATP and Taq DNA polymerase (18).

Proteolytic cleavage of synthetic fibrinopeptides. Synthetic peptides of sequence D F L A E G G G V R G P R VV E R H W and D F L A E G G G V R G P R D V E R H W, corresponding to fibrinogen $\mathrm{A} \alpha$-residues 7-25, were obtained from Chiron Mimotopes (Vic, Australia) and contained blocked $\mathrm{NH}_{2}$ (acetyl) and $\mathrm{COOH}$ (amide) terminals. Trp rather than the normal Gln was incorporated at residue 25 (numbering based on the $\mathrm{NH}_{2}$-terminal of the $\mathrm{A} \alpha$-chain rather than that of the peptide) to facilitate the rapid identification of the $\mathrm{NH}_{2}$ - and $\mathrm{COOH}$ terminal cleavage fragments. The purity and sequence fidelity of the peptides were determined/verified by the manufacturer using ion spray triple quadrupole mass spectrometry. Their measured masses $(\mathrm{MH}+)$ were 2178.4 and $2194.3 \mathrm{D}$, respectively.

For thrombin digests, $1 \mu \mathrm{l}$ bovine thrombin $(0.02 \mathrm{U})$ was added to $0.7 \mathrm{nmol}$ of peptide in $5 \mu \mathrm{l}$ of $50 \mathrm{mM}$ Tris/ $\mathrm{HCl} \mathrm{pH} \mathrm{7.4,50} \mathrm{mM} \mathrm{NaCl}$. Separate tubes were incubated for $2.5,5,10,15,20$, and $30 \mathrm{~min}$ and diluted with $50 \mu \mathrm{l}$ of $49 \mathrm{mM}$ phosphate buffer $\mathrm{pH} 2.9$ before analysis by reverse phase HPLC (8). The amount of peptide cleaved at each time point was determined as a percentage based on the appearance of the $\mathrm{COOH}$-terminal product and disappearance of the parent peptide. For furin digests, the purified $\Delta 704$ mutant soluble form of the mouse enzyme was used (10). The furin, $0.3 \mu \mathrm{l}(4 \mathrm{mU})$, was added to 0.7 nmol of peptide in $2.6 \mu \mathrm{l} 50 \mathrm{mM}$ MES, $1 \mathrm{mM} \mathrm{CaCl} 2, \mathrm{pH} 5.5$ containing $50 \mu \mathrm{M}$, phenanthroline, $20 \mu \mathrm{M}$ pepstatin, $0.1 \mathrm{mg} / \mathrm{ml} \mathrm{E}-64$, and $1 \mathrm{mg} /$ $\mathrm{ml} \alpha$-globin. Individual tubes were incubated at $30^{\circ} \mathrm{C}$ for up to $6 \mathrm{~h}$ before being diluted with $50 \mu \mathrm{l}$ of $49 \mathrm{mM}$ phosphate buffer, $\mathrm{pH} 2.9$ and analyzed by reverse phase HPLC (8). As for thrombin digests the effluent was monitored at 254 as well as $215 \mathrm{~nm}$.

Protein sequence analysis. Fibrinogen $(20 \mu \mathrm{g})$ was separated into its three constituent chains by SDS-PAGE in a $7.5 \%$ gel under reducing conditions and electroblotted onto a polyvinylidene difluoride membrane. Direct sequencing was carried out on an Applied Biosystems 471 instrument using a Problot cartridge.

$\mathrm{CNBr}$ digestion. $1 \mathrm{mg}$ of fibrinogen and $2 \mathrm{mg}$ of $\mathrm{CNBr}$ were incubated overnight in $75 \mu \mathrm{l}$ of $70 \%$ formic acid. After drying (over $\mathrm{NaOH}$ ) peptides were redisolved in $100 \mu \mathrm{l}$ of $1 \%$ SDS, $6 \mathrm{M}$ urea and analyzed directly by nonreducing SDS-PAGE. For cleavage with Bothrops atrox venom (atroxin) $20 \mu \mathrm{g}$ of $\mathrm{CNBr}$ digest was diluted into $50 \mu \mathrm{l} 25 \mathrm{mM}$ Tris $\mathrm{HCl} \mathrm{pH} \mathrm{7.4,} 25 \mathrm{mM} \mathrm{NaCl}$, and $25 \mu \mathrm{g}$ of venom was added. Samples were incubated at $20^{\circ} \mathrm{C}$ for $20 \mathrm{~min}$ and again analyzed by nonreducing SDS-PAGE.

\section{Results}

Case history. The propositus, a 45-y male vegan with Type III hyperlipidemia, was initially seen at a specialized lipid clinic. Fibrinogen was measured as part of a routine panel of cardiovascular risk factors. On specific questioning, he admitted a tendency to prolonged bleeding, lasting up to $15 \mathrm{~min}$, from even minor cuts. He also noted that these cuts would readily resume bleeding after minor bumps. He had no history of major bleeds despite several episodes of surgery including an amputation of one arm after trauma sustained in a motor vehicle accident. He denied any easy bruising although soft tissue injuries such as a sprained ankle often resulted in large hematomas. He has two siblings and two children, who were not available for testing, but was not aware of any familial bleeding or thrombotic tendency.

Fibrinogen levels measured functionally by thrombin clotting gave values of 0.8 and $0.7 \mathrm{mg} / \mathrm{ml}$ on two occasions while quantitation based on the amount of fibrinopeptide $B$ release was $1.3 \mathrm{mg} / \mathrm{ml}$ for both these samples. The prothrombin time (INR) and APP time were normal at 1.2 and $32 \mathrm{~s}$, respectively (normal ranges $0.8-1.2$ and 26-37 s). The prolonged thrombin and reptilase time of $32 \mathrm{~s}$ (normal 18-22 s) and $29 \mathrm{~s}$ (normal 18-22 s) however, suggested an impairment of fibrinopeptide release and/or fibrin polymerisation.

Fibrinopeptide release. Reverse phase thrombin catalysed fibrinopeptide release assays (Fig. 1) were performed on whole plasma and incorporated $10 \mathrm{mM}$ phenanthroline to inhibit the carboxypeptidase B mediated conversion of peptide B to its des-Arg form. Analysis of 10 different normal plasmas indicated that the average fibrinopeptide A to $B$ ratio, based on peak areas, was 0.92. Analysis of three separate cases (Brennan, $S$. O., B. Hammonds and P. M. George unpublished data) with the fibrinogen Christchurch mutation ( $B 14 \mathrm{Arg} \rightarrow \mathrm{Cys}$ ) gave average $A$ to $B$ ratios of 2.1 indicating, as expected, that the $B$ peptide was not being removed from $\sim 50 \%$ of the $\mathrm{B} \beta$ chains. In contrast, repeated analysis of plasma from the present case (Fig. $1 b$ ) showed a decrease in fibrinopeptide A release with an $A: B$ ratio of 0.58 . This result explains the observed prolonged thrombin and reptilase times and suggested that either the propositus is heterozygous for a mutation that prevents the thrombin catalysed release of the A peptide, or that the A peptide was missing from approximately half of the $\mathrm{A} \alpha$ chains in the circulating fibrinogen.

DNA sequence analysis. Genomic DNA encoding residues -1 to 41 of the $\mathrm{A} \alpha$ chain and 9 to 72 of the $\mathrm{B} \beta$ chain, spanning the two thrombin cleavage sites (18), was amplified by the polymerase chain reaction and the products subjected to direct DNA sequence analysis as described earlier. The $\mathrm{B} \beta$ DNA had an entirely normal sequence, however, two bands, $\mathrm{A}$ and $\mathrm{T}$, were detected at nucleotide 1215 of the A $\alpha$ gene (Fig. 2). This 


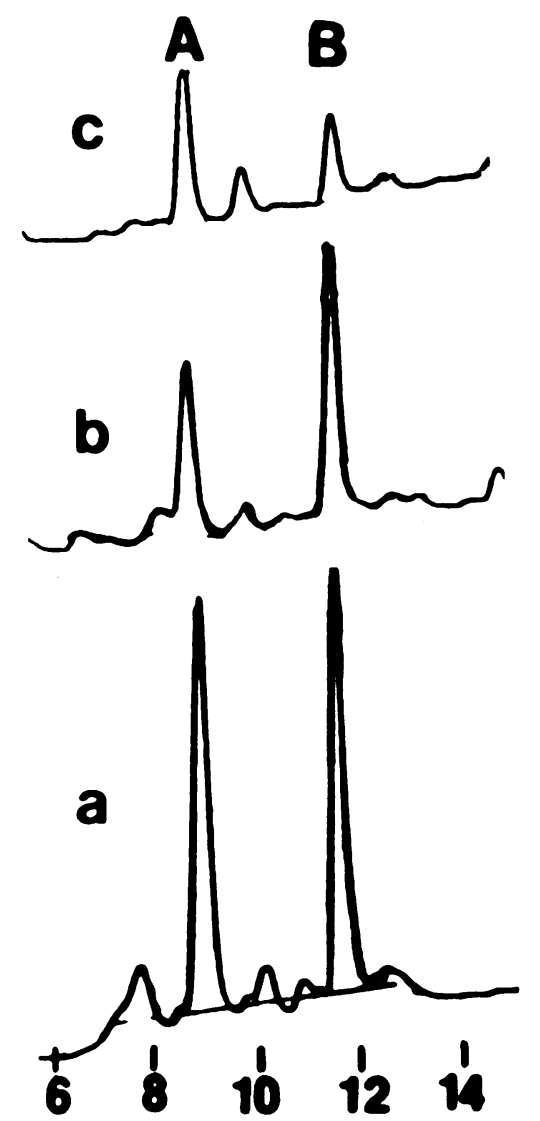

Figure 1. Reverse phase HPLC analysis of fibrinopeptide release. $(a)$ normal control; $(b)$ propositus with fibrinogen Canterbury; and (c) control patient with fibrinogen Christchurch B $\beta 14$ Arg $\rightarrow$ Cys. $50 \mu \mathrm{l}$ of plasma was incubated with thrombin and the released peptides $(A$ and $B$ ) separated by reverse phase HPLC. Gradient $25-50 \%$ B over $14 \mathrm{~min}$.

indicates that the propositus is heterozygous for a mutation of A $\alpha 20 \mathrm{Val} \rightarrow$ Asp (GTT $\rightarrow$ GAT). This result was confirmed by sequencing the complementary strand and represents a new mutation; fibrinogen Canterbury.

Cleavage of synthetic fibrinopeptides. The prolonged thrombin time and decreased yield of fibrinopeptide A could be readily explained if this mutation inhibited thrombin cleavage as is reported to occur in other fibrinogens with mutations at

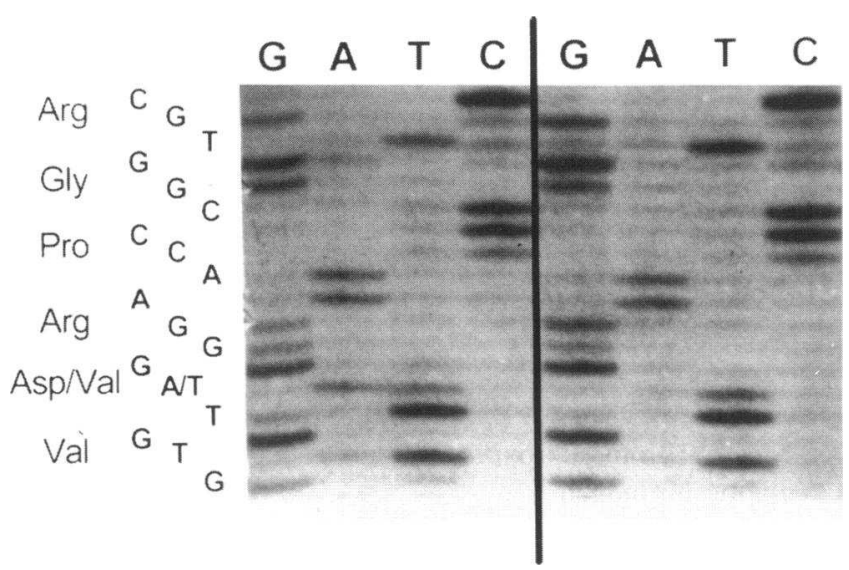

Figure 2. DNA sequencing of the fibrinogen A $\alpha$ gene, exon 2. Normal control (right) and a heterozygote for fibrinogen Canterbury (left), showing that the affected individual is heterozygous for $\mathrm{A}$ and $\mathrm{T}$ at the second base of the codon for amino acid 20. The abnormal sequence encodes a mutation of $\mathrm{A} \alpha 20 \mathrm{Val}$ to Asp.

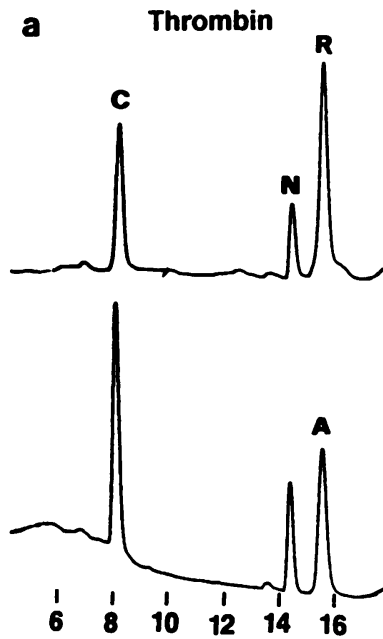

b

Furin

Figure 3. Reverse phase separation of thrombin $(a)$ and furin $(b)$ digests of synthetic peptides incorporating the normal, A F L A E G G G V $\mathrm{R}^{16}$ G P R V ${ }^{20}$ V E R H W sequence (peptide $A$ ) and the variant peptide with the $20 \mathrm{Val} \rightarrow$ Asp substitution (peptide $R$ ). The thrombin digests shown are for a 5-min incubation and the gradient is from 14 to $55 \% \mathrm{~B}$. The furin digests shown were for $2 \mathrm{~h}$ and gradient was from 14 to $62 \% \mathrm{~B}$. $\mathrm{N}$ and $\mathrm{C}$ peptides are derived from cleavage at Arg 16 and $N^{\prime}$ and $C^{\prime}$ from cleavage at Arg 19, respectively.

or near the cleavage site $(19,20)$; e.g. fibrinogens Ledyard 16 $\mathrm{A} \alpha \mathrm{Arg} \rightarrow$ Cys and Aarhus $19 \mathrm{~A} \alpha \mathrm{Arg} \rightarrow$ Gly $(21,22)$. To test this possibility, synthetic peptides spanning residues 7-25 of the normal and fibrinogen Canterbury sequence were incubated with thrombin and the reaction monitored over time by reverse phase HPLC. The normal (A) peptide D F L A E G G G V $\mathrm{R}^{16}$ G P R V V E R H W was cleaved exclusively at Arg 16 to give two more polar products (Fig. $3 a$ ). Sequence and composition analysis established that these products were D F L A E G G G V R and G P R V V E R H W (peptides N and $\mathrm{C}$, respectively). Analysis of thrombin digests of the fibrinogen Canterbury (R) peptide D F L A E G G G V R G P R D V E $\mathrm{R} H \mathrm{~W}$ gave a similar result with composition analysis confirming that the peak at $8 \mathrm{~min}$ corresponded to the new $\mathrm{COOH}$ terminal peptide G P R D V E R H W and that the 14.5-min peak corresponded to the $\mathrm{NH}_{2}$-terminal fragment, D F L A E G G G V R. However, while both peptides were cleaved at the expected site, there was a small decrease in the rate of cleavage of the abnormal peptide. The relative rate of cleavage (abnormal to normal) was 0.56 with a standard deviation of 0.08 in 8 separate analyses. This small change appeared insufficient to explain the decrease in fibrinopeptide A release since this was measured by an end point assay.

Fibrinogen is also subjected to cleavage by intracellular endoproteases. Signal peptidase catalyses cotranslational removal of the presequence and the hepatic convertase, which is thought to be the protease furin is active in the Golgi. This enzyme has a specificity for X Y R R Z or R X Y R Z sequences with a special condition that $Z$, the $P_{1}{ }^{\prime}$ residue, cannot be valine (16). We therefore postulated that the mutation in fibrinogen Canterbury, which converts the normal R G P R V sequence to $R$ G P R D, introduces a furin cleavage site. This was confirmed when the peptide containing this new sequence was incubated with a recombinant soluble form of furin and the products separated by reverse phase HPLC. Two fragments were ob- 
served (Fig. $3 b$ ) and sequence/composition analysis established that $\mathrm{N}^{\prime}$ was D F L A E G G G V R G P R and that $\mathrm{C}^{\prime}$ was D V E R H W confirming that cleavage was occurring at Arg 19. The rate of this reaction, $0.6 \mathrm{nmol} / \mathrm{min}$ per unit of furin, was comparable to that observed for the cleavage of a peptide RGVFRRDAHKSEVAW ( $0.5 \mathrm{nmol} / \mathrm{min}$ per unit $)$ which incorporates the processing site of proalbumin (8). There was, however, no detectable cleavage of the normal fibrinogen peptide even after prolonged incubations of $6 \mathrm{~h}$.

Analysis of fibrinogen. Fibrinogen was purified by ammonium sulphate precipitation and analyzed by agarose gel electrophoresis, nonreducing SDS-PAGE in $4 \%$ gels and reducing 7.5\% SDS-PAGE gels. Normal patterns were observed in all cases, specifically the expected $340-$ and $305-\mathrm{kD}$ forms were observed in nonreducing SDS gels (23), and on reducing gels the individual $\mathrm{A} \alpha, \mathrm{B} \beta$, and $\gamma$ chains comigrated with the corresponding chains from normal individuals. However, protein sequence analysis of the individual chains, after transfer to a polyvinylidene difluoride membrane, showed two major sequences in the $A \alpha$ band of the propositus. One was the expected $\mathrm{NH}_{2}$-terminal sequence of Ala Asp Ser Gly Glu Gly Asp Phe Leu- and the second was Asp Val Glu Arg His Gln (Ser) Ala. Two PTH amino acids were clearly detectable at each cycle except for residue seven where only Asp was detected and the other residue was presumed to be Ser. The aberrant sequence commences at the $\mathrm{A} \alpha 20 \mathrm{Val} \rightarrow$ Asp mutation site and proceeds with a normal primary structure beyond residue 21 . The two products were present in the ratio $60: 40$, normal to truncated variant.

The six $\mathrm{NH}_{2}$ termini of the pairs of $\mathrm{A} \alpha, \mathrm{B} \beta$ and $\gamma$ chains that make up the central domain of the fibrinogen molecule, are held rigidly together by a series of disulfide bonds. $\mathrm{This}$ ' $\mathrm{NH}_{2}$ terminal disulfide knot' can be liberated as a unit by $\mathrm{CNBr}$ cleavage. It consists of residues ( $\mathrm{A} \alpha 1-51, \mathrm{~B} \beta 1-118$, and $\gamma 1$ 78) $\times 2$ and, containing 494 amino acids, it is the largest expected $\mathrm{CNBr}$ fragment (2) apart from higher $\mathrm{Mr}$ forms which result from incomplete cleavage, possibly resulting from partial demethylation of the methionines. Fig. $4 A$ shows the SDSPAGE pattern of $\mathrm{CNBr}$ digests of nonreduced fibrinogen. The propositus (lanes 1 and 4 ) showed the expected normal 494 residue fragment $(a)$ together with two lower molecular weight forms $(b$ and $c$ ) which were not present in controls (lanes 2, 3 , and 5). As expected the (a) band runs above the albumin marker (lane 6 ) which, because of its intense disulfide bonding, has an apparent $M_{\mathrm{r}}$ of $50 \mathrm{kD}$ in nonreducing gels $(24,25)$. Incubation with Bothrops atrox venom confirmed that band a was the 494 residue $\mathrm{NH}_{2}$-terminal disulfide knot since removal of the two A peptides resulted in a decrease in $M_{\mathrm{r}}$ (Fig. $4 B$, lanes 1 and 2). Similar incubation of the $\mathrm{CNBr}$ digest from the propositus resulted in normalisation of the band pattern (lanes 4 and 3 ). The atroxin cleavage products all migrated below band $b$ and in the position of the minor $c$ band. These data confirm the amino acid sequence data which indicated truncation of the $A \alpha$ chain and further show that the circulating fibrinogen contains both homo- and heterodimers of the abnormal $\mathrm{A} \alpha$ chains. Similarly homo- and heterodimers have been observed with fibrinogen Birmingham (26).

\section{Discussion}

DNA sequence analysis readily established that the propositus was heterozygous for a mutation of $\mathrm{A} \alpha 20 \mathrm{Val} \rightarrow$ Asp. Since

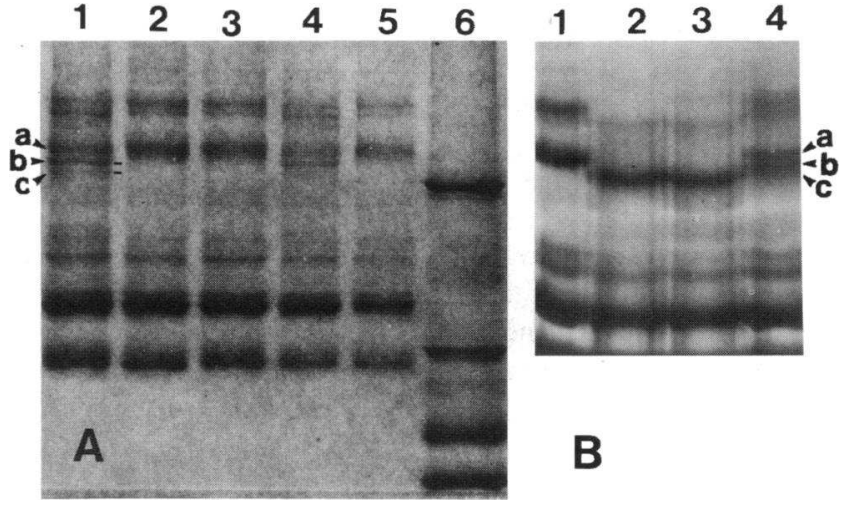

Figure 4. (A) SDS-PAGE of CNBr digests of purified fibrinogen; lanes 1 and 4, propositus; lanes 2,3 , and 5 normal control individuals. Lane 6 shows markers of serum albumin, pepsin, trypsinogen, and lysozyme. Nonreducing $10 \%$ gel. $(B) \mathrm{CNBr}$ digests of fibrinogen before and after incubation with Bothrops atrox venom; normal fibrinogen, lanes 1 (before) and 2 (after); and fibrinogen Canterbury, lanes 4 (before) and 3 (after), respectively. Nonreducing $7.5 \%$ gel.

this substitution is close to the thrombin cleavage site at Arg 16 , it initially seemed plausible that the prolonged thrombin time might be explained by defective thrombin binding and cleavage. This has been reported for other variants (19-22) and is consistent with the observation that fibrinopeptide $A$ was not released from some $40 \%$ of the $A \alpha$ chains after treatment with excess thrombin.

Failure of thrombin cleavage was, however, not verified in experiments with synthetic peptides which showed that both the variant and normal peptide were cleaved with similar efficiencies $(0.5$ and $0.9 \mathrm{nmol} / \mathrm{min}$ per unit, respectively $)$. The predicted change in amino acid sequence from Arg Gly Pro Arg Val to Arg Gly Pro Arg Asp suggested an alternative explanation for the prolonged thrombin time; that the variant $A \alpha$ chain was being cleaved, within the intracellular export pathway, by the hepatic proprotein convertase (7). This novel suggestion was substantiated in three ways: $(a)$ by sequence analysis of the $\mathrm{A} \alpha$ chains from circulating fibrinogen which showed that $40 \%$ of the molecules commenced at the new aspartic acid at residue $20 ;(b)$ by the demonstration of truncation in the $\mathrm{NH}_{2}$-terminal disulfide knot after $\mathrm{CNBr}$ cleavage; and $(c)$ by the demonstration that peptides incorporating the new sequence were rapidly cleaved by purified recombinant furin the proposed in situ hepatic convertase.

The sequence requirements for cleavage by the endogenous KEX2-like hepatic convertase $(7)$ and furin $(8,10)$ are identical, with absolute requirements for paired basic residues in either an X Y Arg Arg or preferably an Arg X Y Arg sequence. For processing to occur however the $\mathrm{P}_{1}{ }^{\prime}$ residue immediately after the cleavage site must not be valine. The clearest demonstration of this precise requirement comes from the observed failure of proalbumin processing in individuals with the proalbumin Blenheim $(+1 \mathrm{Asp} \rightarrow \mathrm{Val})$ mutation. Here the existing Val Phe Arg Arg Asp site is replaced by an ineffective Val Phe Arg Arg Val sequence (16). In fibrinogen Canterbury the converse mutation occurs and thus the new A $\alpha$ sequence of Arg Gly Pro Arg Asp would be expected to permit the intracellular removal of the A peptide together with the Gly Pro Arg polymerization site. It would also be necessary for Arg 19 to be on 
the surface of the molecule and thus accessible to proteases. However, this appears to be the case since in prolonged digestions with thrombin normal fibrinogen can be cleaved at this site.

It also appears that fibrinogen is exposed to furin in the hepatic export pathway since the cDNA for the A $\alpha$ chain encodes an additional 15 residue propeptide not found in the circulating molecule (5). In this instance, cleavage occurs at an Arg Pro Val Arg Gly-sequence and is followed by carboxypeptidase $\mathrm{H}$ exoproteolytic removal of the exposed Arg to generate the observed mature COOH-terminal sequence of Arg Pro Val. When fibrinogen is expressed in kidney cells (5) which, like the hepatocyte, contain high levels of furin (27), the secreted protein contains two species of $\mathrm{A} \alpha$ chain: one with the extension and one with the mature circulating sequence. As would be expected for furin mediated cleavage, mutation of the $\mathrm{P}_{1} \mathrm{Arg} \rightarrow$ Gly totally prevented fibrinogen cleavage in the baby hamster kidney expression system. Further investigation showed that this extended molecule underwent normal assembly and secretion, and that there was no alteration in its ability to clot in the presence of thrombin or crosslink in the presence of factor XIIIa. Similarly intracleavage of the new 'propeptide' sequence at the $\mathrm{NH}_{2}$-terminal of fibrinogen Canterbury does not appear to have a major effect on assembly or secretion since the truncated molecule constitutes $40 \%$ of the circulating $\alpha$ chains and homodimers $\left(\alpha^{*} \mathrm{~B} \beta \gamma\right) 2$ as well as heterodimers were detected after $\mathrm{CNBr}$ cleavage. However, removal of the $\mathrm{NH}_{2}$-terminal twenty residues has a predictably major impact on function since the intracellular cleavage removes the Gly Pro Arg sequence which is the primary initiator of polymerisation.

This mutation reveals a new disease mechanism but also implies a general constraint on the sequence of secreted proteins. Specifically valine residues that follow exposed dibasic sequences might be important in preventing unwanted cleavage of any protein that transits the constitutive export pathway. Similarly other large alkyl $\mathrm{P}_{1}{ }^{\prime}$ residues, noticeably leucine and isoleucine, also inhibit proalbumin cleavage (28) and histidine is not allowed at the $P_{2}$ position (8). Thus, in the $B \beta$ chain, histidine 19, which occurs in a sequence of Arg Gly His Arg, might have the specific role of preventing similar intracellular cleavage, and mutations at this residue might allow similar intracellular cleavage of the $\mathrm{B} \beta$ chain.

\section{Acknowledgments}

We thank Dr. Kazuhisu Nakayama for providing the $\Delta 704$ furin and Christine Hickton for hematological results.

This work was supported by the Canterbury Medical Research Foundation and the Health Research Council of New Zealand.

\section{References}

1. Doolittle, R. F. 1994. The molecular biology of fibrin. In The Molecular Basis of Blood Disease. G. Stamatoyannopoulos, A. W. Nienhuis, P. W. Majerus, and H. Varmus, editors. W. B. Saunders Co., Philadelphia. 701-723.

2. Henschen, A., and J. McDonagh. 1986. Fibrinogen, fibrin and factor XIII, In Blood Coagulation, F. F. A. Zwaal and H. C. Hemker, editors. Elsevier Scienve Publishers, Amsterdam. 171-241.

3. Yamazumi, K., and R. F. Doolittle. 1992. Photoaffinity labeling of the primary fibrin polymerization site: localization of the lable to $\gamma$-chain Tyr 363 Proc. Natl. Acad. Sci. USA. 89:2893-2896.

4. Hartwig, R., and K. Danishefsky. 1991. Studies on the assembly and secretion of fibrinogen. J. Biol. Chem. 266:6578-6585.

5. Farrell, D., S. Huang, and E. W. Davies. 1993. Processing of the carboxyl 15-amino acid extension in the chain of fibrinogen. J. Biol. Chem. 268:1035110355.

6. Brennan, S. O., and R. J. Peach. 1988. KEX2-like protease in heptic secretory vesicles converts proalbumin. FEBS Lett. 229:167-170.

7. Brennan, S. O., and R. J. Peach. 1991. The processing of human proinsulin and chicken proalbumin by rat hepatic vesicles suggests a convertase specific for X Y Arg Arg or Arg X Y Arg sequences. J. Biol. Chem. 266:21504-21508.

8. Brennan, S. O., and K. Nakayama. 1994. Cleavage of proalbumin peptides by furin reveals unexpected restrictions at the $\mathrm{P}_{2}$ and $\mathrm{P}_{1}{ }^{\prime}$ sites. FEBS Lett. 347:8084.

9. Chiron, M. F., C. M. Fryling, and D. J. FitzGerald. 1994. Cleavage of pseudomonas exotoxin and diphtheria toxin by a furin-like enzyme from beef liver. J. Biol. Chem. 269:18167-18176.

10. Brennan, S. O., and K. Nakayama. 1994. Furin has the proalbumin substrate specificity and serpin inhibitory properties of an in situ hepatic convertase. FEBS Lett. 338:147-151.

11. Davison, H. W., and J. C. Hutton. 1987. The insulin secretory granule carboxypeptidase $\mathrm{H}$ : purification and demonstration of involvement in proinsulin processing. Biochem. J. 245:572-582.

12. Halbon, P. A., and J. -C. Irminger. 1994. Sorting and processing of secretory proteins. Biochem. J. 299:1-18.

13. Diuguid, D. L., M. J. Rabiet, B. C. Furie, H. A. Liebman, and B. Furie. 1968. Molecular basis of hemophilia B: defective enzyme due to a mutation in the factor IX precursor. Proc. Natl. Acad. Sci. USA. 83:5803-5807.

14. Bentley, A. K., D. J. C. Rees, C. Rizza, and G. G. Brownlee. 1986 Defective propeptide processing of blood clotting factor IX caused by mutation of Arg $\rightarrow$ Gln at position 4. Cell. 45:343-348.

15. Yoshimasa, Y., S. Seino, J. Whittaker, T. Kakehi, A. Kosaki, H. Kuzuya, H. Imura, G. I. Bell, and D. F. Steiner. 1988. Insulin resitant diabetes due to a point mutation that prevents insulin proreceptor processing. Science (Wash. DC). 240:783-787.

16. Brennan, S. O., R. J. Peach, and D. R. Boswell. 1989. Novel human proalbumin variant with intact dibasic sequence facilitates identification of its converting enzyme. Biochim. Biophys. Acta. 993:48-50.

17. Chung, D. W., J. E. Harris, and E. W. Davie. 1990. Nucleotide sequence of the three genes coding for human fibrinogen. Adv. Exp. Med. Biol. 281:3948.

18. Murray, V. 1989. Improved double stranded DNA sequencing using the linear polymerase chain reaction. Nucleic Acids Res. 17:8889.

19. Soria, J., C. Soria, M. Samama, A. Henschen, and C. Southan 1982 Detection of abnormalities in dysfibrinogenaemia: special report on fibrinogen Metz characterised by aminoacid substitution located at the peptide bond cleaved by thrombin. In Fibrinogen: Recent Biochemical and Medical Aspects. A. Henschen, H. Graeff, and F. Lottspeich, editors. Walter de Gruyten, Berlin. 129143.

20. Higgins, D. L., and J. A. Shafer. 1981. Fibrinogen Petoskey, a dysfibrinogenaemia characterised by replacement of $\operatorname{Arg} A \alpha 16$ by a histidyl residue. $J$. Biol. Chem. 256:12013-12017.

21. Lee, M. H., E. Kaczmarek, T. D. Chin, A. Oda, S. McIntosh, K. A. Bauer, L. P. Clyne, and J. McDonagh. 1991. Fibrinogen Ledyard (A $\alpha 16$ Arg $\rightarrow$ Cys). Biochemical and physiolgoical characterization. Blood. 78:1744-1752.

22. Hessel, B., S. Stenberg, J. Dyr, B. Kudryk, L. Therkildsen, and B. Blombäck, 1986. Fibrinogen Aarhus: a new case of dysfibrinogenaemia. Thromb. Res. 42:21-37.

23. Holm, B., D. W. T. Nilsen, P. Kierulf, and H. C. Godal. 1985. Purification and characterisation of 3 different fibrinogens with different molecular weights obtained from normal human plasma. Thromb. Res. 37:165-176.

24. Brennan, S. O., and A. P. Fellowes. 1993. Albumin Hawkes Bay: a low level variant caused by loss of a sulphydryl group at position 177. FEBS Lett. 1182:46-50.

25. Andre, C. M., A. R. McGiven, and S. McQuilken. 1980. Immunological investigation of renal disease. In Practical Methods in Clinical Immunology. A. R. McGiven, editor. Churchill Livingstone, New York. 76-91.

26. Siebenlist, K. R., J. T. Prchal, and M. W. Mosesson. 1988. Fibrinogen Birmingham: a heterozygous dysfibrinogenaemia (A $\alpha 16$ Arg to His) containing heterodimeric molecules. Blood. 71:613-618.

27. Seidah, N. G., M. Chretien, and R. Day. 1994. The family of subtilisin/ kexin like proprotein and prohormone convertases: divergent and shared functions. Biochimie (Paris). 76:197-209.

28. Oda, K., Y. Misumi, M. Sohda, N. Takami, Y. Sakaki, and Y. Ikehara, 1991. Selective processing of proalbumin determined by site-specific mutagenesis. Biochem. Biophys. Res. Commun. 175:690-696. 